Supplement of The Cryosphere, 10, 1859-1881, 2016

http://www.the-cryosphere.net/10/1859/2016/

doi:10.5194/tc-10-1859-2016-supplement

(C) Author(s) 2016. CC Attribution 3.0 License.

(c) (1)

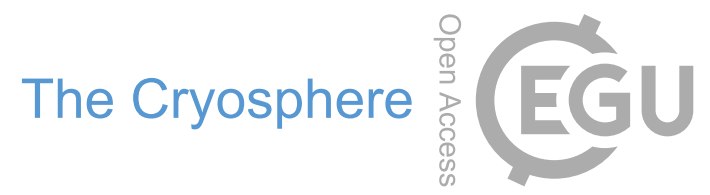

Supplement of

\title{
Multilevel spatiotemporal validation of snow/ice mass balance and runoff modeling in glacierized catchments
}

Florian Hanzer et al.

Correspondence to: Florian Hanzer (florian.hanzer@uibk.ac.at)

The copyright of individual parts of the supplement might differ from the CC-BY 3.0 licence. 


\section{S1 Cold content and liquid water content}

The module for consideration of cold content and liquid water content of the snowpack is controlled by three parameters: the water holding capacity, $\mathrm{HC}_{w}$, the cold holding capacity, $\mathrm{HC}_{c}$ (both specified as a fraction of the total snowpack weight), and the refreezing factor, $F_{r}$, which is the fraction of the computed heat loss used for refreezing and building up the cold content.

Potential melt $M_{p}[\mathrm{~mm}]$ is calculated using the available melt energy $Q_{M}$ as

$$
M_{p}=\frac{Q_{M}}{c_{i}},
$$

where $c_{i}$ is the melting heat of ice $\left(333.7 \mathrm{~kJ} \mathrm{~kg}^{-1}\right)$.

In the case of a negative energy balance $\left(Q_{M}<0\right)$, this "negative melt" is first used to calculate a refreezing of liquid water in the snowpack, RF [mm], in the form of

$$
\mathrm{RF}=\min \left\{C_{\mathrm{lw}, t-1},-M_{p} \cdot F_{r}\right\},
$$

where $C_{\mathrm{lw}, t-1}[\mathrm{~mm}]$ is the liquid water content of the previous time step. $C_{\mathrm{lw}}$ for a given time step is derived as

$$
C_{\mathrm{lw}}=C_{\mathrm{lw}, t-1}+P_{r}-\mathrm{RF},
$$

where $P_{r}[\mathrm{~mm}]$ is liquid precipitation. The remaining amount of energy is used to increase the cold content $C_{c}$ (cold content is represented with negative values, while liquid water content is represented with positive values) as

$$
C_{c}=\max \left\{C_{\mathrm{c}, t-1}+\left(M_{p} \cdot F_{r}+\mathrm{RF}\right),-\mathrm{HC}_{c} \cdot \mathrm{SWE}_{t-1}\right\} .
$$

In the case of a positive energy balance $\left(Q_{M}>0\right)$, first the sum of cold content reduction and actual melt is calculated as

$$
M_{v}=\min \left\{\mathrm{SWE}_{t-1}-C_{\mathrm{c}, t-1}, M_{p}\right\}
$$

$C_{c}$ is then reduced with

$$
C_{c}=\min \left\{C_{\mathrm{c}, t-1}+M_{v}, 0\right\}
$$

and actual melt, $M_{a}[\mathrm{~mm}]$, calculated as

$$
M_{a}=M_{v}-\left(C_{c}-C_{\mathrm{c}, t-1}\right) .
$$

$C_{\mathrm{lw}}$ is then updated in form of

$$
C_{\mathrm{lw}}=\min \left\{C_{\mathrm{lw}, t-1}+M_{a}, \mathrm{SWE}_{t-1} \cdot \mathrm{HC}_{w}\right\}
$$

and the outflow (i. e., the excess water that is actually removed from the snowpack), $O[\mathrm{~mm}]$, is finally calculated as

$$
O=\max \left\{\left(C_{\mathrm{lw}, t-1}+P_{r}+M_{a}\right)-\mathrm{SWE}_{t-1} \cdot \mathrm{HC}_{w}, 0\right\} .
$$

The long-term discharge simulations were not improved due to the implementation of the module for cold content and liquid water content, as can be seen in table S1 (skill scores for the individual catchments and the validation period 2007-2013 obtained using invidually calibrated runoff parameters for the period 1997-2006) - in fact average model skill even decreased slightly after implementation of the module. The module was rather implemented to improve the snow cover simulations and prevent premature melting of snow in high elevations. As table S2 shows, snow depth evolution was only slightly improved 
at the high-elevated stations, while at the low-elevated stations snow depth overestimations increased even more, resulting in lower model performance. However, the implementation of the cold content/liquid water content module drastically improved the simulations regarding (i) snow depth distribution over the winter 2010/11 (fig. S1), (ii) long-term glacier mass balance 1997-2006 (fig. S2), and (iii) annual (fig. S3) and cumulative (fig. S4) glacier mass balance for HEF, KWF, and VF, as can be seen when comparing these figures (obtained without consideration of cold content and liquid water content) with the ones shown in the original manuscript.

Table S1: NSE, BE, and PBIAS of simulated vs. observed runoff for the validation period 2007-2013 obtained using model runs without and with consideration of cold content and liquid water content, respectively.

\begin{tabular}{clcccccc}
\hline & & \multicolumn{3}{c}{ Without CC/LWC } & \multicolumn{3}{c}{ With CC/LWC } \\
ID & Catchment & NSE & BE & PBIAS & NSE & BE & PBIAS \\
\hline 1 & Rofenache & 0.78 & 0.35 & 20.0 & 0.78 & 0.35 & 20.0 \\
2 & Gurgler Ache & 0.80 & 0.26 & 19.1 & 0.80 & 0.26 & 20.8 \\
4 & Gepatschalm & 0.87 & 0.48 & 6.9 & 0.87 & 0.50 & 7.3 \\
6 & Taschachbach & 0.88 & 0.45 & 0.2 & 0.88 & 0.45 & 2.2 \\
7 & Pitze & 0.87 & 0.53 & 4.7 & 0.87 & 0.53 & 4.4 \\
8 & Radurschlbach & 0.67 & -0.39 & 20.3 & 0.67 & -0.43 & 22.7 \\
13 & Fissladbach & 0.67 & -0.14 & 28.8 & 0.63 & -0.23 & 31.9 \\
\hline & Mean & 0.79 & 0.22 & 14.3 & 0.79 & 0.20 & 15.6 \\
\hline
\end{tabular}

Table S2: $R^{2}$, Nash-Sutcliffe efficiency NSE, and percent bias PBIAS for observed vs. simulated snow depth obtained using model runs without and with consideration of cold content and liquid water content, respectively.

Without CC/LWC $\quad$ With CC/LWC

\begin{tabular}{lccccccc} 
Station & $\begin{array}{c}\text { Elevation } \\
{[\mathrm{m} \text { a.s.1.] }}\end{array}$ & $R^{2}$ & NSE & $\begin{array}{c}\text { PBIAS } \\
{[\%]}\end{array}$ & $R^{2}$ & NSE & $\begin{array}{c}\text { PBIAS } \\
{[\%]}\end{array}$ \\
\hline Prutz & 871 & 0.70 & -1.09 & 170.87 & 0.66 & -2.21 & 222.5 \\
Nauders & 1330 & 0.79 & 0.04 & 99.02 & 0.74 & -0.35 & 119.5 \\
Obergurgl & 1942 & 0.76 & 0.74 & -13.32 & 0.85 & 0.85 & -6.0 \\
Weisssee & 2480 & 0.69 & 0.57 & 13.45 & 0.76 & 0.52 & 28.7 \\
Pitztaler & 2864 & 0.74 & 0.72 & -9.54 & 0.71 & 0.68 & 7.1 \\
Gletscher & & & & & & & \\
\hline
\end{tabular}




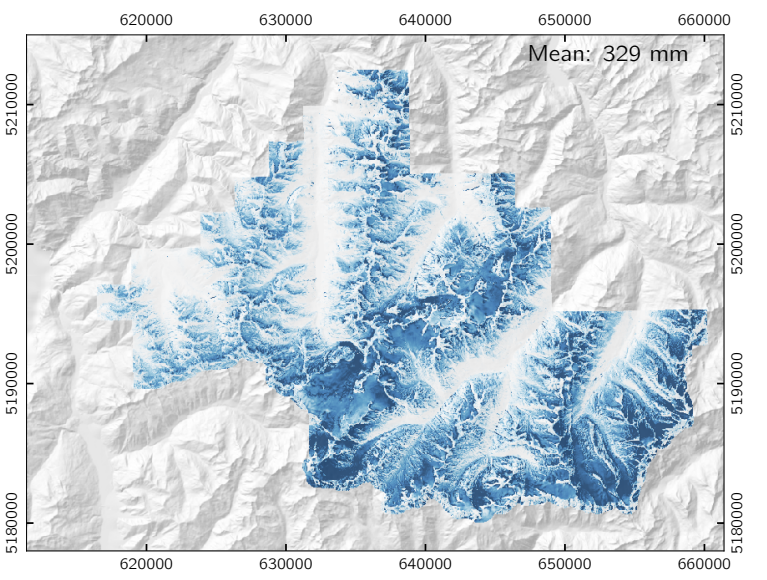

Snow/ice w.e. change observed [mm]

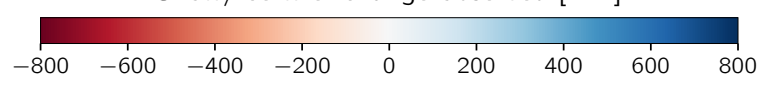

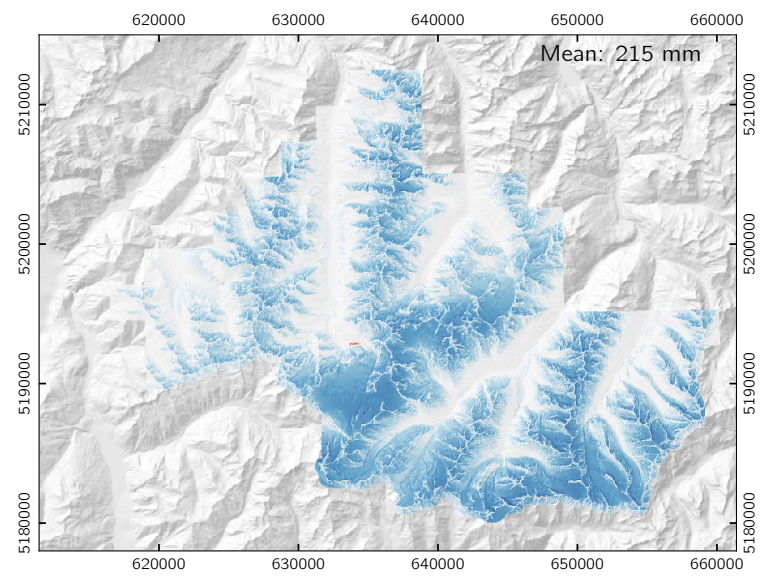

Snow/ice w.e. change simulated [mm]

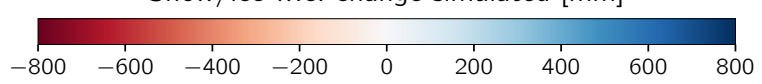

Figure S1: Observed and simulated end-of-season snow distribution for the winter 2010/11 (October 8 to April 22) without consideration of cold content and liquid water content in the model.
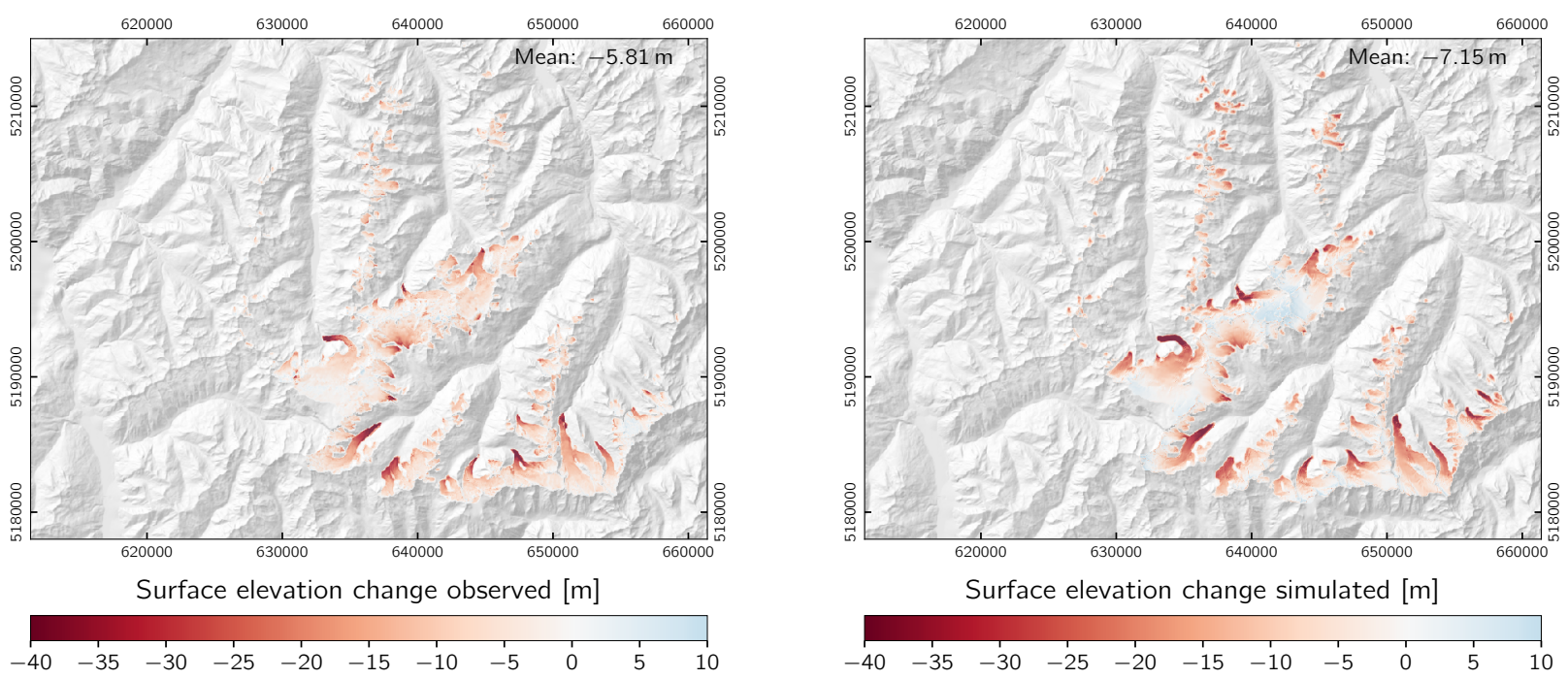

Figure S2: Observed and simulated glacier surface elevation change for the period 1997-2006 without consideration of cold content and liquid water content in the model. 


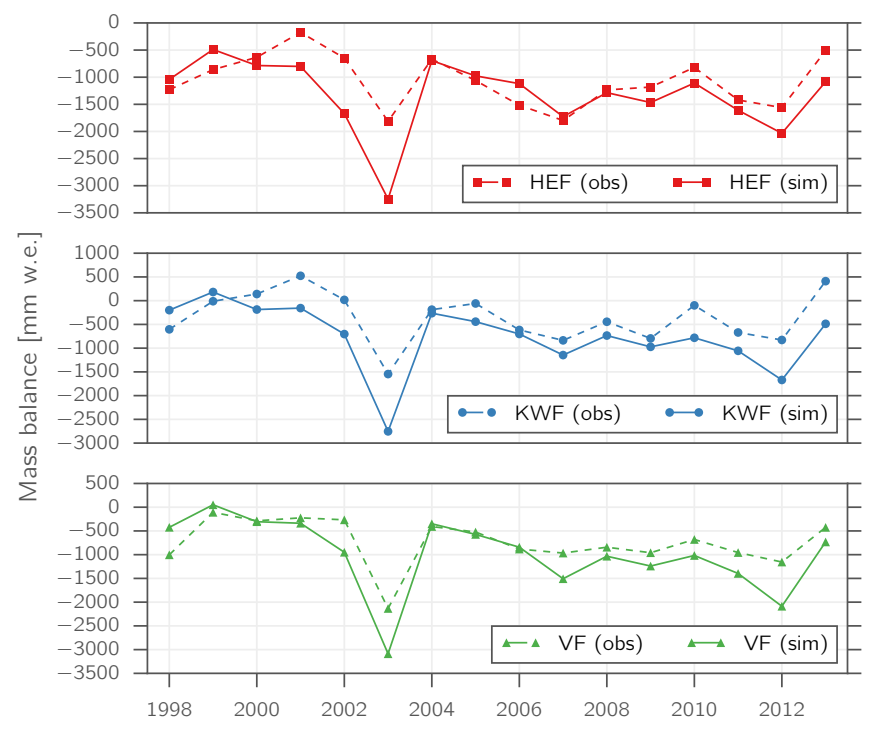

Figure S3: Observed (dashed) and simulated (solid) specific mass balance for Hintereisferner (HEF, top), Kesselwandferner (KWF, center), and Vernagtferner (VF, bottom) in the period 1997/98-2012/13 without consideration of cold content and liquid water content in the model.

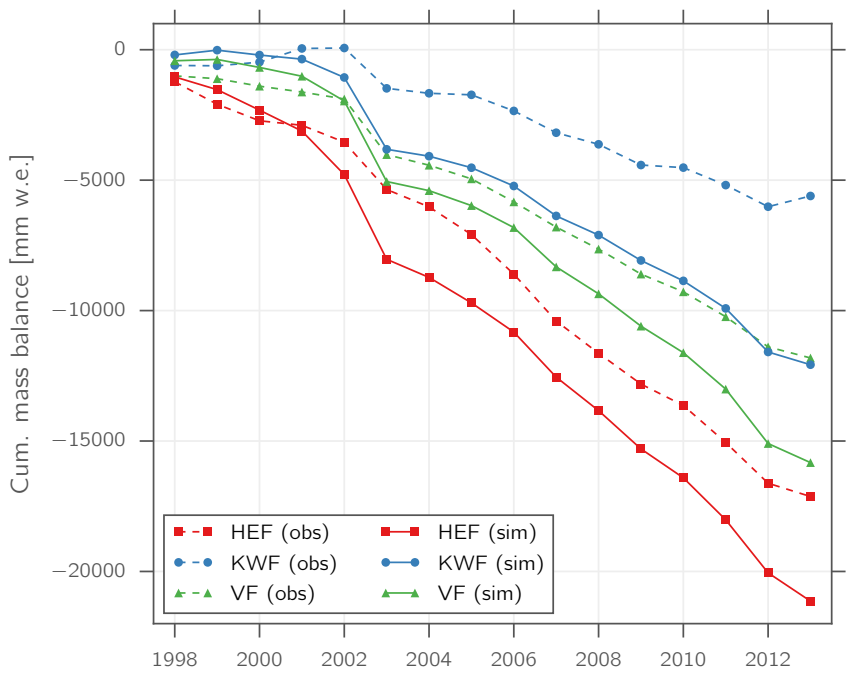

Figure S4: Observed (dashed) and simulated (solid) cumulative specific mass balance for Hintereisferner (HEF), Kesselwandferner (KWF), and Vernagtferner (VF) in the period 1997/98-2012/13 without consideration of cold content and liquid water content in the model. 


\section{S2 Analysis of the mass balance simulations for the year 2003}

The simulated mass balances for the three glaciers with annual measurements are particularly underestimated in the year 2003. Looking at the satellite comparison using Landsat and MODIS data for this year (fig. S5), model performance is indeed decreasing during the summer of 2003, however as the BIAS results and the plots of the two Landsat scenes in late July and mid-September, respectively, show (figs. S6-S7), this is due to an over- rather than an underestimation of snow cover (at least on these two dates). Runoff simulations (fig. S8) for the gauge Vent/Rofenache (of which the three glaciers are contributing to) also show no striking anomalies, but rather a quite satisfying agreement with the observations during the summer months of 2003. After further investigation, comparison of simulated snow depth for three stations (fig. S9), showed that for the stations Obergurgl and Pitztaler Gletscher snow depth is captured very well (Obergurgl) and slightly overestimated (Pitztaler Gletscher), respectively, however distinctly underestimated for the station Vernagtbach (being the closest station to the three investigated glaciers, hence having the highest influence on the interpolated meteorological fields) in this year, mostly due to a precipitation event in mid-November 2002 which is not captured by the precipitation recordings at this station (blue line in fig. S9). Re-running the model while excluding the precipitation recordings for October and November 2002 at this station (i.e., precipitation for the station location is then obtained by interpolation from the surrounding stations) yields considerably higher snow depths (green line in fig. S9). Fig. S10 shows the cumulative daily glacier mass balances for HEF, KWF, and VF for the glaciological year 2003. The simulated mass balances are still underestimated, but approx. $250 \mathrm{~mm}$ (HEF), $450 \mathrm{~mm}$ (VF), and $500 \mathrm{~mm}$ (KWF) less negative than in the original model run, indicating that the deviations in simulated mass balance for this year can at least partly explained by this issue.
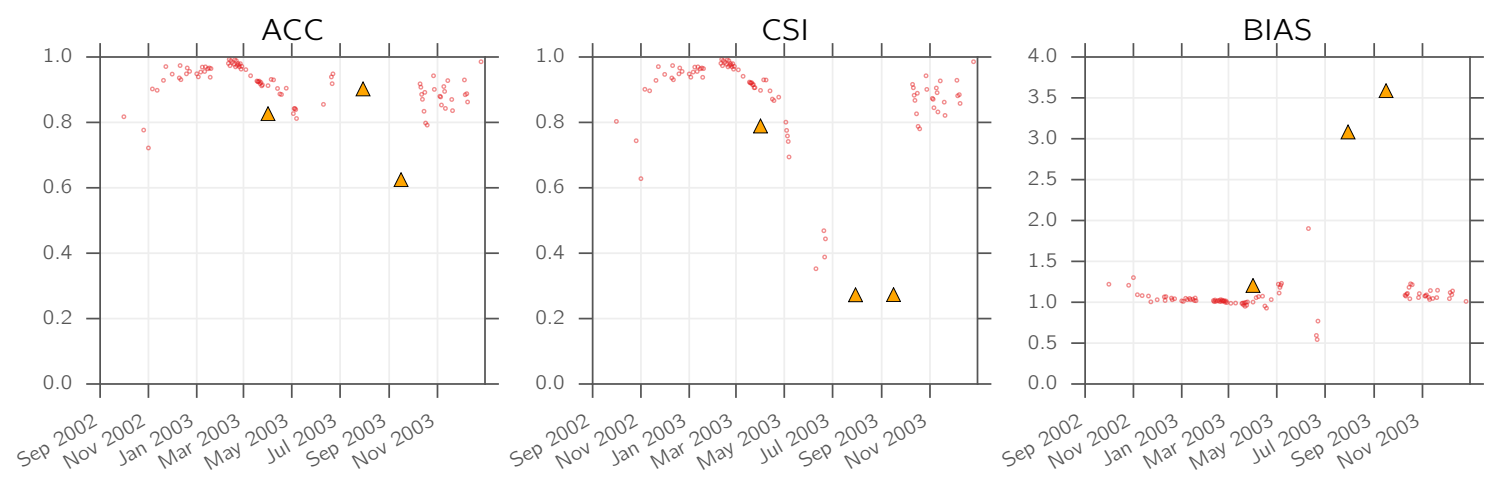

Figure S5: ACC, CSI, and BIAS for all available Landsat (triangles) and MODIS (circles) scenes of the year 2003. 

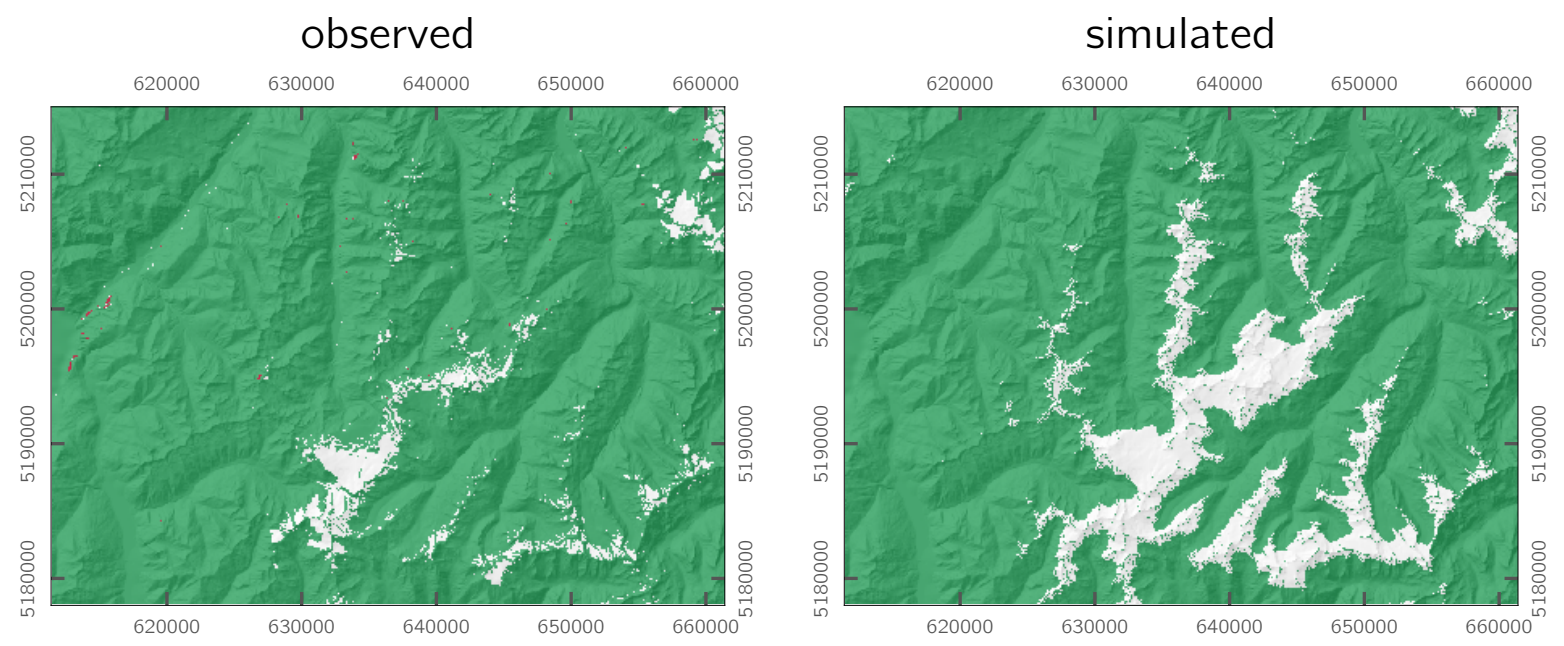

Figure S6: Observed (Landsat) and simulated snow cover distribution for July 30, 2003.
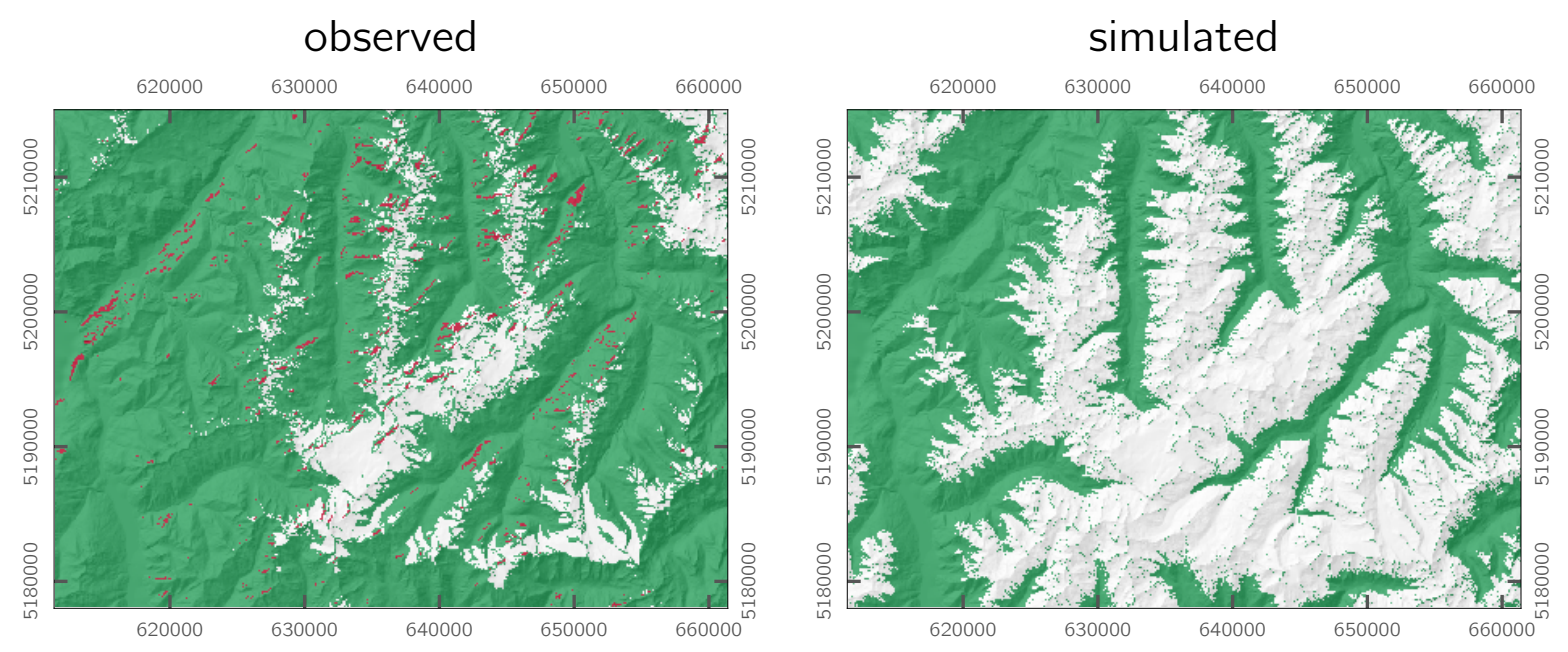

Figure S7: Observed (Landsat) and simulated snow cover distribution for September 16, 2003. 


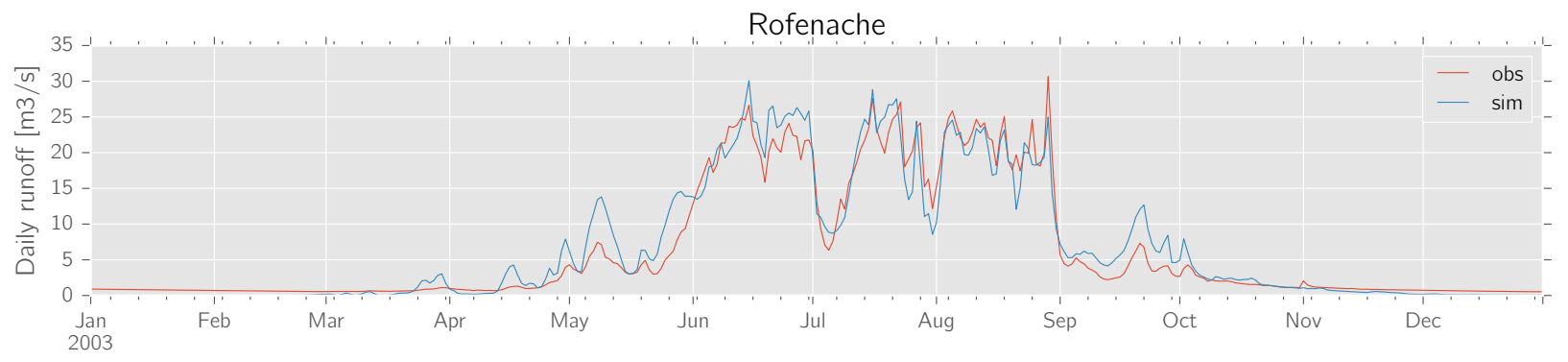

Figure S8: Observed and simulated mean daily runoff for gauge Rofenache (including HEF, KWF, and VF glaciers) in the year 2003. 

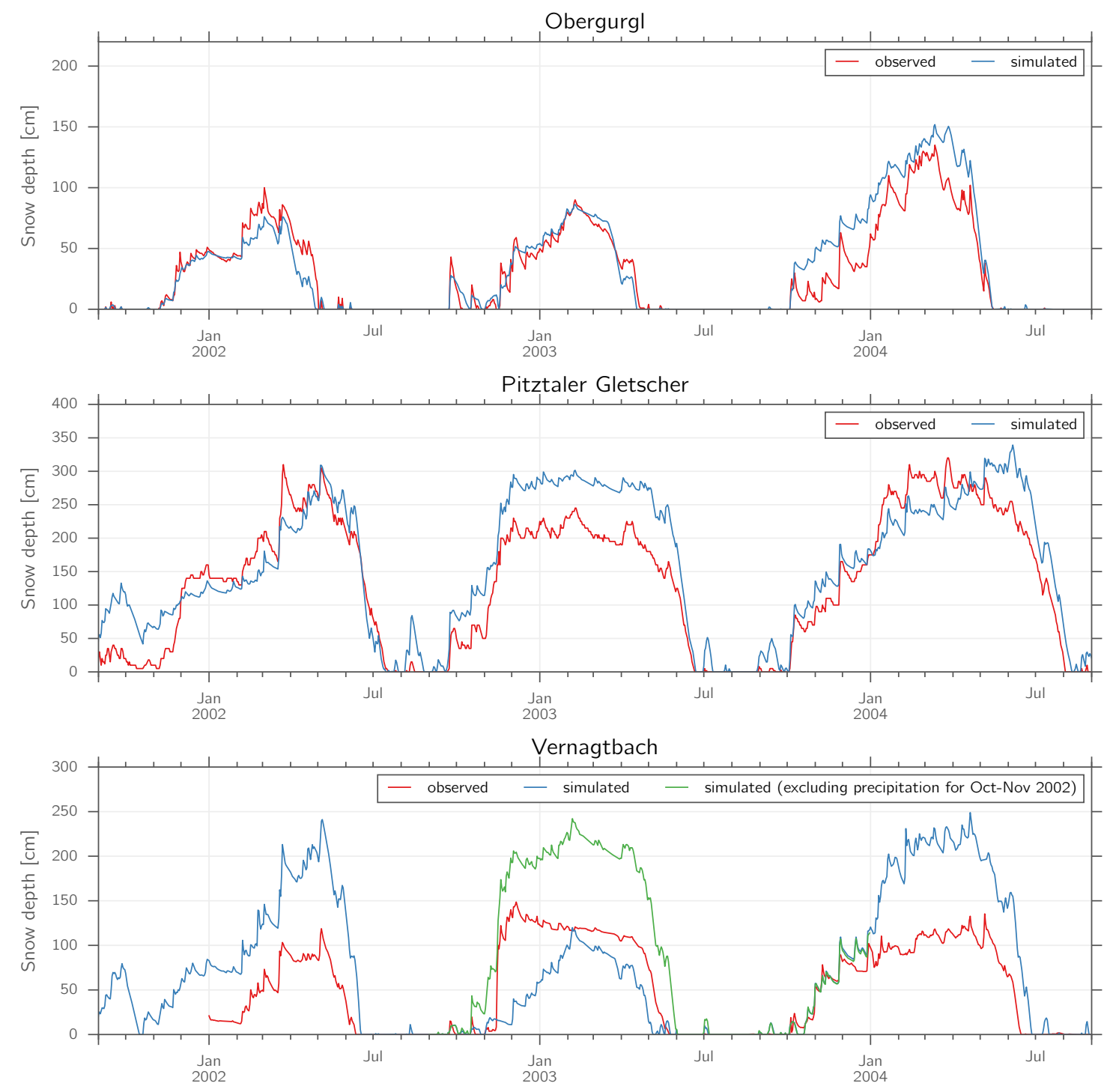

Figure S9: Observed and simulated snow depth for the stations Obergurgl (1942 m a.s.1.), Pitztaler Gletscher (2864 m a.s.1.) and Vernagtbach (2640 m a.s.l.) in the period 2001-2004. 


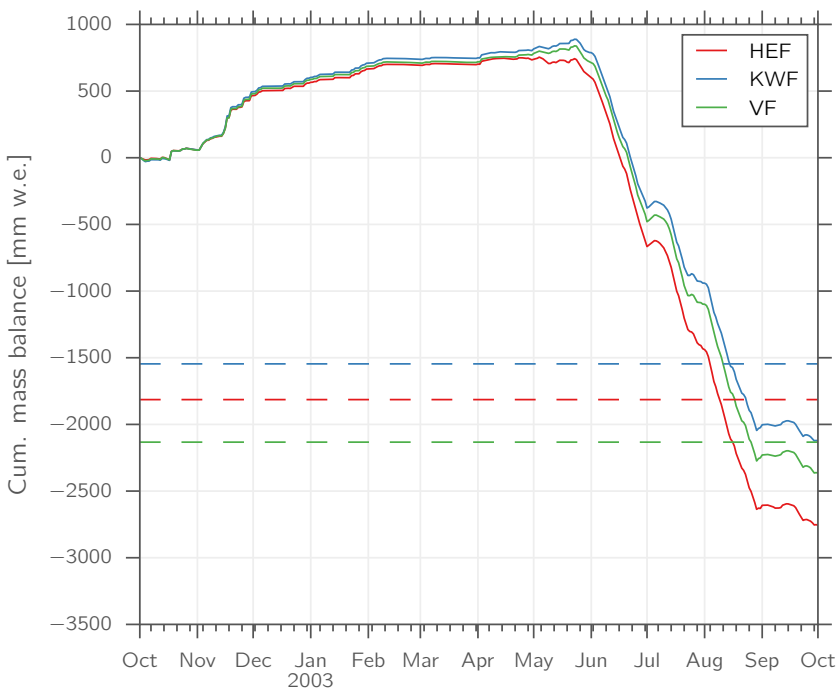

Figure S10: Cumulative daily mass balance for the glaciological year 2003 and the glaciers HEF, KWF, and VF as simulated by AMUNDSEN while exluding the Vernagtbach station precipitation recordings for October-November 2002 (solid lines), and observed glaciological mass balances for this year (dashed lines). 


\section{S3 Satellite data comparison}

Table S3: Landsat scenes used for the validation of the simulated spatial snow distribution.

\begin{tabular}{|c|c|c|c|}
\hline Date & Scene ID & Spacecraft & $\begin{array}{r}\text { Snow-covered } \\
\text { area [\%] }\end{array}$ \\
\hline 1998-03-26 & LT51930271998085KIS00 & Landsat 5 & 87.6 \\
\hline 1999-09-13 & LE71930271999256EDC00 & Landsat 7 & 5.8 \\
\hline $2000-05-10$ & LE71930272000131EDC00 & Landsat 7 & 56.7 \\
\hline 2000-08-14 & LE71930272000227EDC00 & Landsat 7 & 7.2 \\
\hline 2001-05-13 & LE71930272001133EDC00 & Landsat 7 & 64.3 \\
\hline 2001-06-30 & LE71930272001181EDC00 & Landsat 7 & 27.5 \\
\hline 2002-01-08 & LE71930272002008AGS00 & Landsat 7 & 86.2 \\
\hline 2002-03-13 & LE71930272002072EDC00 & Landsat 7 & 78.6 \\
\hline 2002-06-01 & LE71930272002152EDC00 & Landsat 7 & 44.8 \\
\hline 2003-04-01 & LE71930272003091EDC00 & Landsat 7 & 66.6 \\
\hline 2003-07-30 & LT51930272003211MTI01 & Landsat 5 & 4.2 \\
\hline 2003-09-16 & LT51930272003259MTI01 & Landsat 5 & 14.3 \\
\hline 2004-06-30 & LT51930272004182KIS00 & Landsat 5 & 28.5 \\
\hline 2004-09-10 & LE71930272004254ASN01 & Landsat 7 (SLC off) & 3.8 \\
\hline 2004-10-04 & LT51930272004278KIS00 & Landsat 5 & 15.0 \\
\hline 2006-06-12 & LE71930272006163ASN00 & Landsat 7 (SLC off) & 38.7 \\
\hline $2007-07-25$ & LT51930272007206MOR00 & Landsat 5 & 7.7 \\
\hline $2008-02-26$ & LE71930272008057ASN00 & Landsat 7 (SLC off) & 79.2 \\
\hline 2009-08-23 & LE71930272009235ASN00 & Landsat 7 (SLC off) & 4.4 \\
\hline 2009-08-31 & LT51930272009243MOR00 & Landsat 5 & 3.2 \\
\hline 2011-01-17 & LE71930272011017ASN00 & Landsat 7 (SLC off) & 85.2 \\
\hline 2011-04-07 & LE71930272011097ASN00 & Landsat 7 (SLC off) & 67.0 \\
\hline 2011-07-04 & LT51930272011185MOR00 & Landsat 5 & 11.3 \\
\hline 2011-10-16 & LE71930272011289ASN01 & Landsat 7 (SLC off) & 41.2 \\
\hline 2012-05-11 & LE71930272012132ASN00 & Landsat 7 (SLC off) & 55.9 \\
\hline 2012-10-18 & LE71930272012292ASN00 & Landsat 7 (SLC off) & 66.2 \\
\hline
\end{tabular}



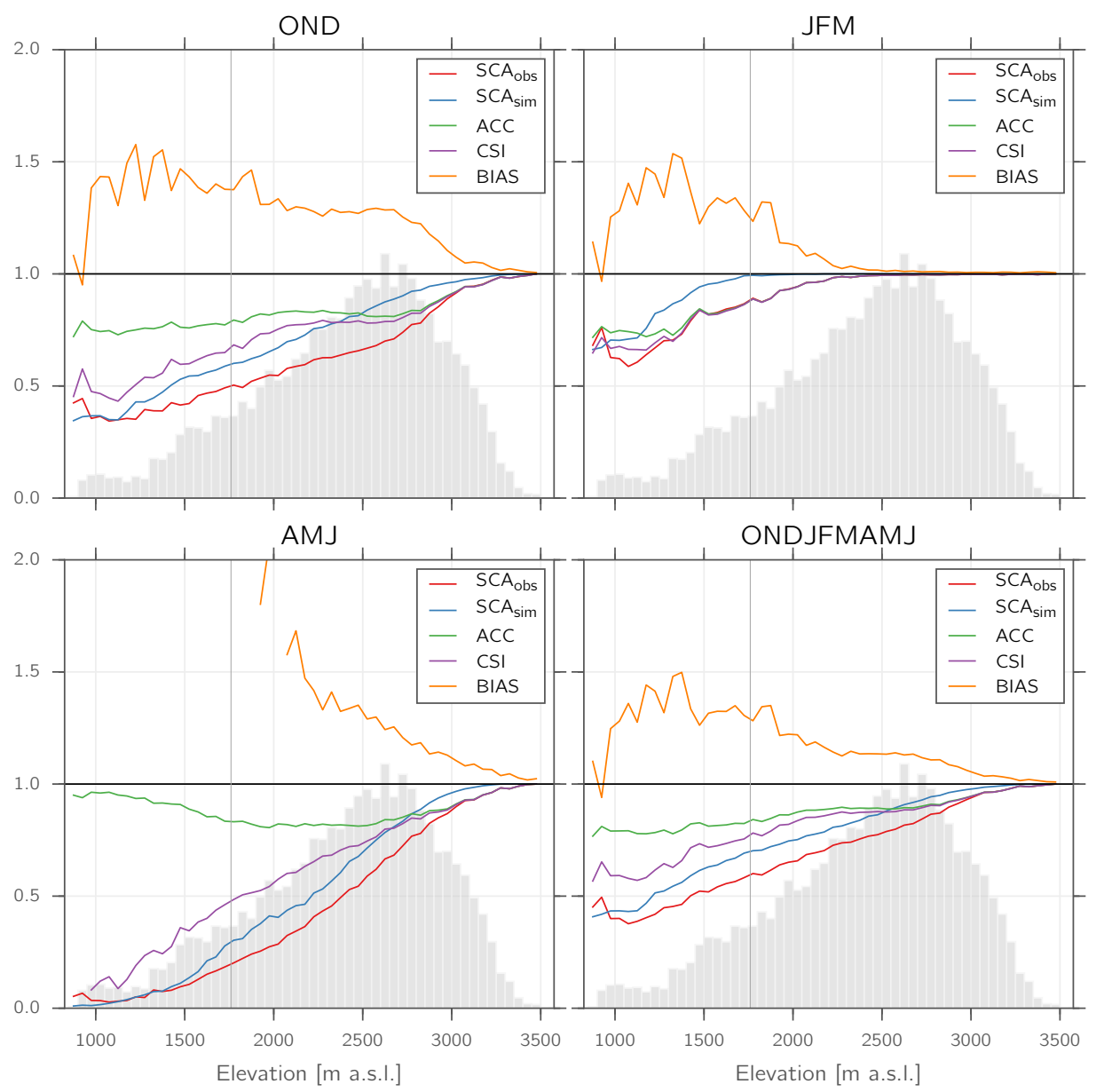

Figure S11: Average values of SCA, ACC, CSI, and BIAS by elevation of all suitable MODIS scenes shown for Oct-Dec (top left), Jan-Mar (top right), Apr-Jun (bottom left), and Oct-Jun (bottom right). The vertical lines indicate the elevation of the lowest-elevated runoff gauge at $1760 \mathrm{~m}$ a.s.l., and the gray bars represent the relative area distribution of the elevation bands (shown without scale). 


\section{S4 ALS data comparison}
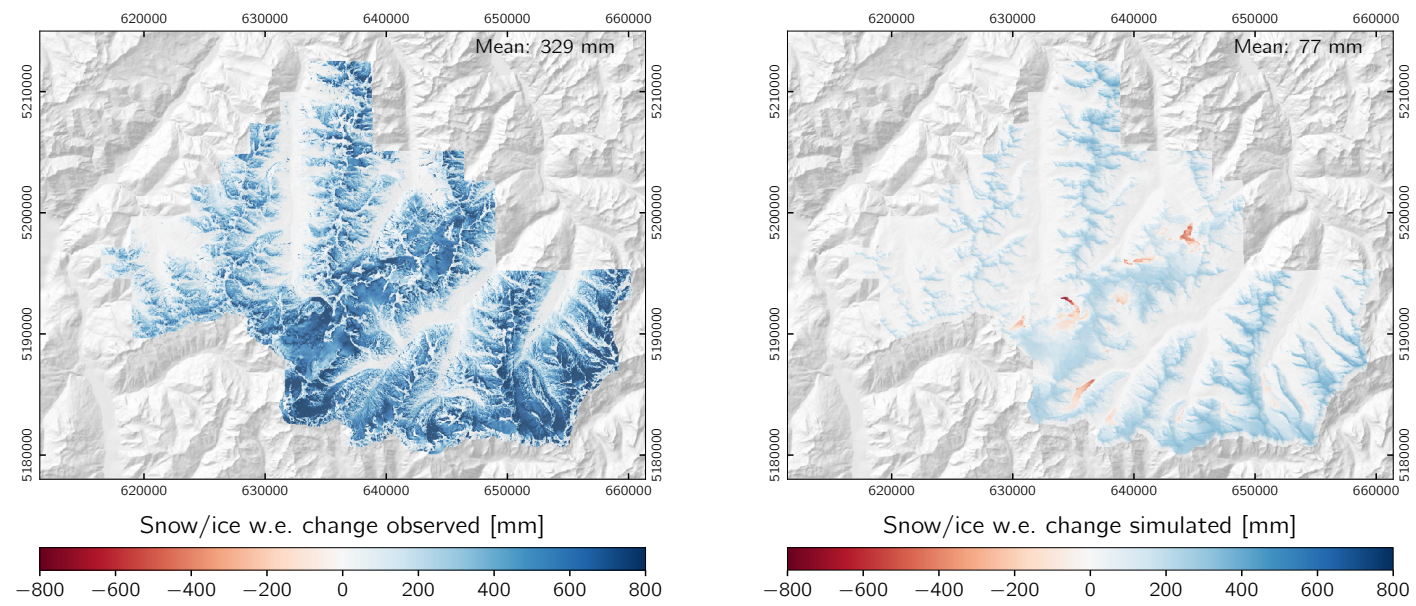

Figure S12: Observed and simulated end-of-season snow distribution for the winter 2010/11 (October 8 to April 22) without correcting and redistributing snowfall.
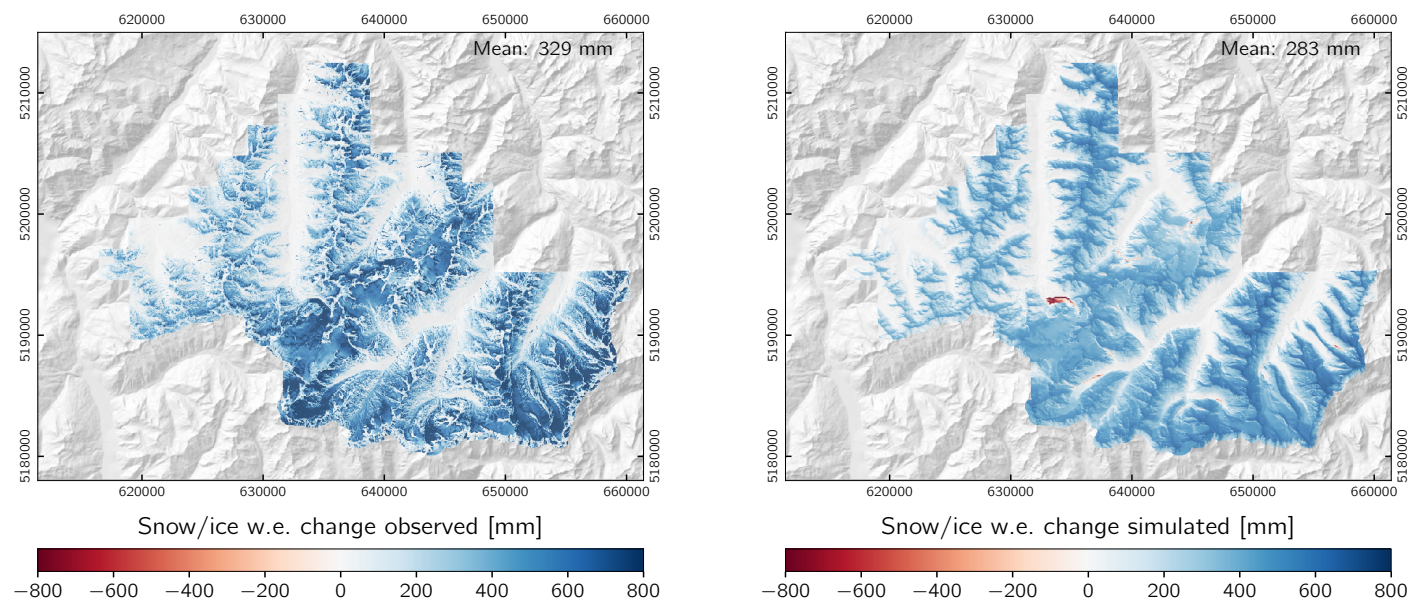

Figure S13: Observed and simulated end-of-season snow distribution for the winter 2010/11 (October 8 to April 22) with snowfall correction for gauge undercatch but no redistribution. 

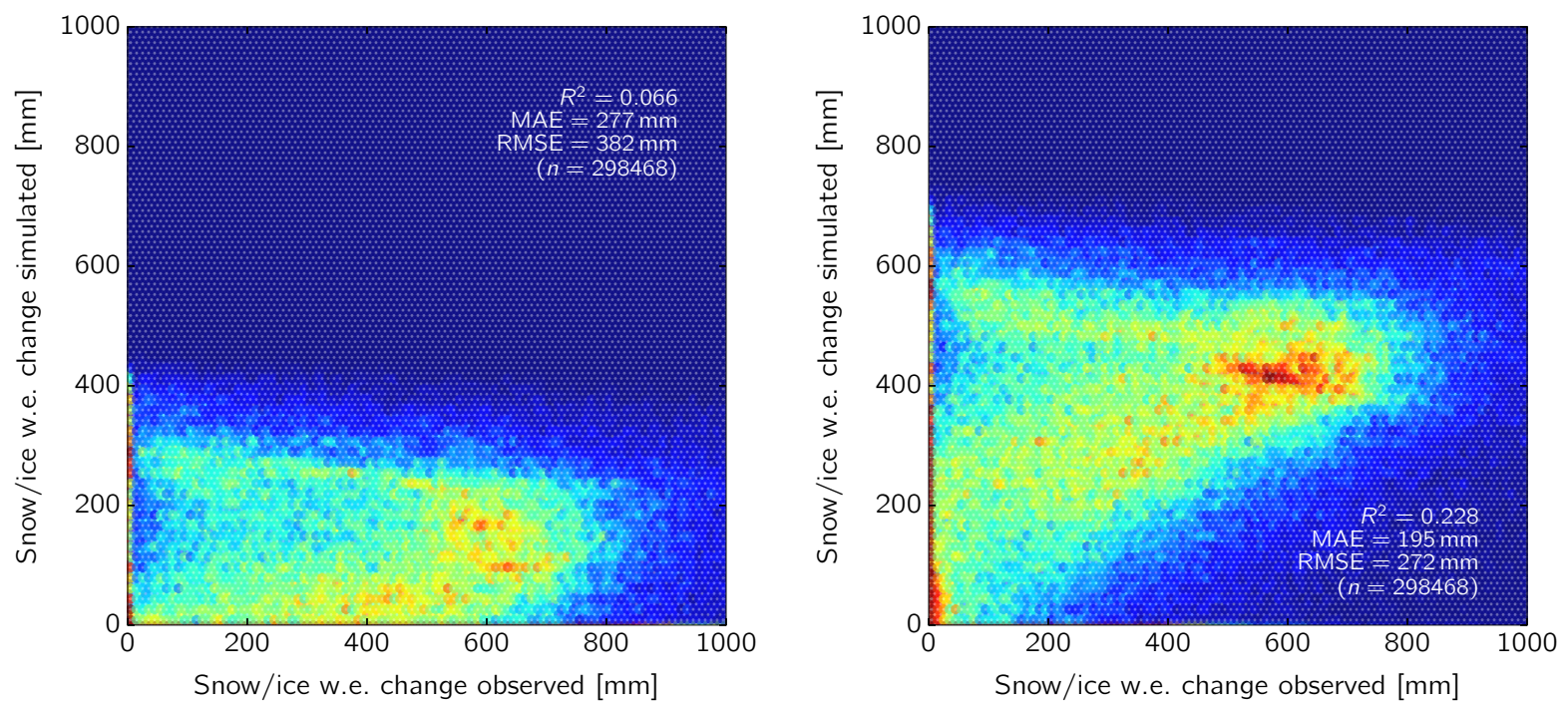

Figure S14: Binned scatter plot (colors represent point density) of observed vs. simulated water equivalent differences for the winter 2010/11 (October 8 to April 22), without correcting and redistributing snowfall (left) and with snowfall correction for gauge undercatch but no redistribution (right).

\section{S5 Runoff module parameters and resulting skill}

Fig. S15 exemplarily shows the parameter values for the 50 best-performing (in terms of eq. (11) from the manuscript) parameter combinations for the Rofenache and Gepatschalm catchments, as well as the skill scores NSE, PBIAS, and BE for the validation period 2007-2013. While the NSE and PBIAS values of all combinations are comparatively similar, a remarkably large spread of the of the resulting values for the benchmark efficiency BE can be observed. However, the best-performing parameter sets in terms of eq. (11) (dark green lines) are also among the best-performing sets in terms of BE. Fig. S16 shows the resulting runoff of the best-performing parameter set as well as the range of the 50 best-performing parameter sets for the two catchments and the year 2012. 

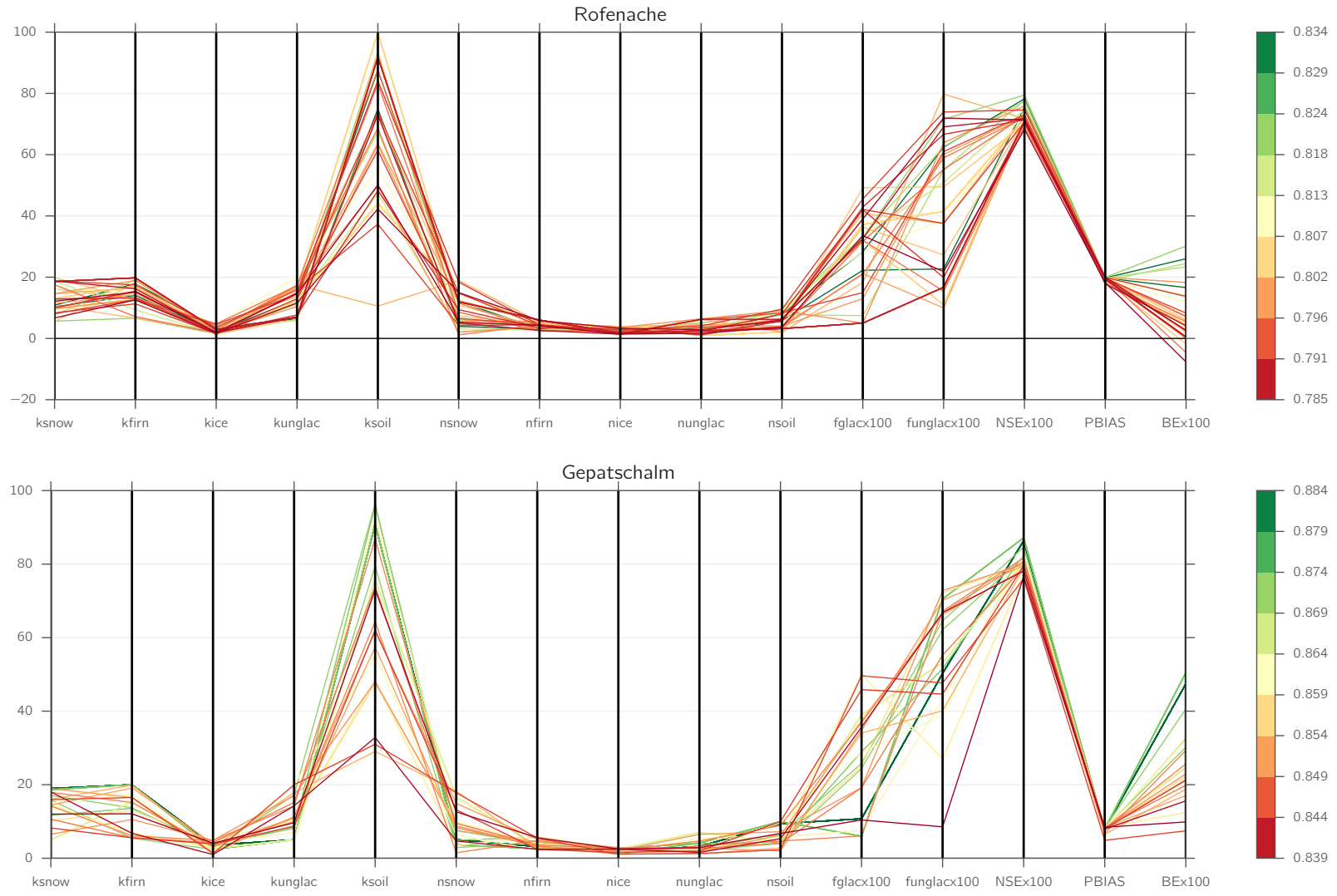

Figure S15: Parameter values for the 50 best-performing (in terms of eq. (11)) parameter sets, as well as the skill scores NSE, PBIAS, and BE obtained for the validation period 2007-2013, for the Rofenache (top) and Gepatschalm (bottom) catchments. Line colors correspond to the calibration period (1997-2006) model skill in terms of eq. (11). 

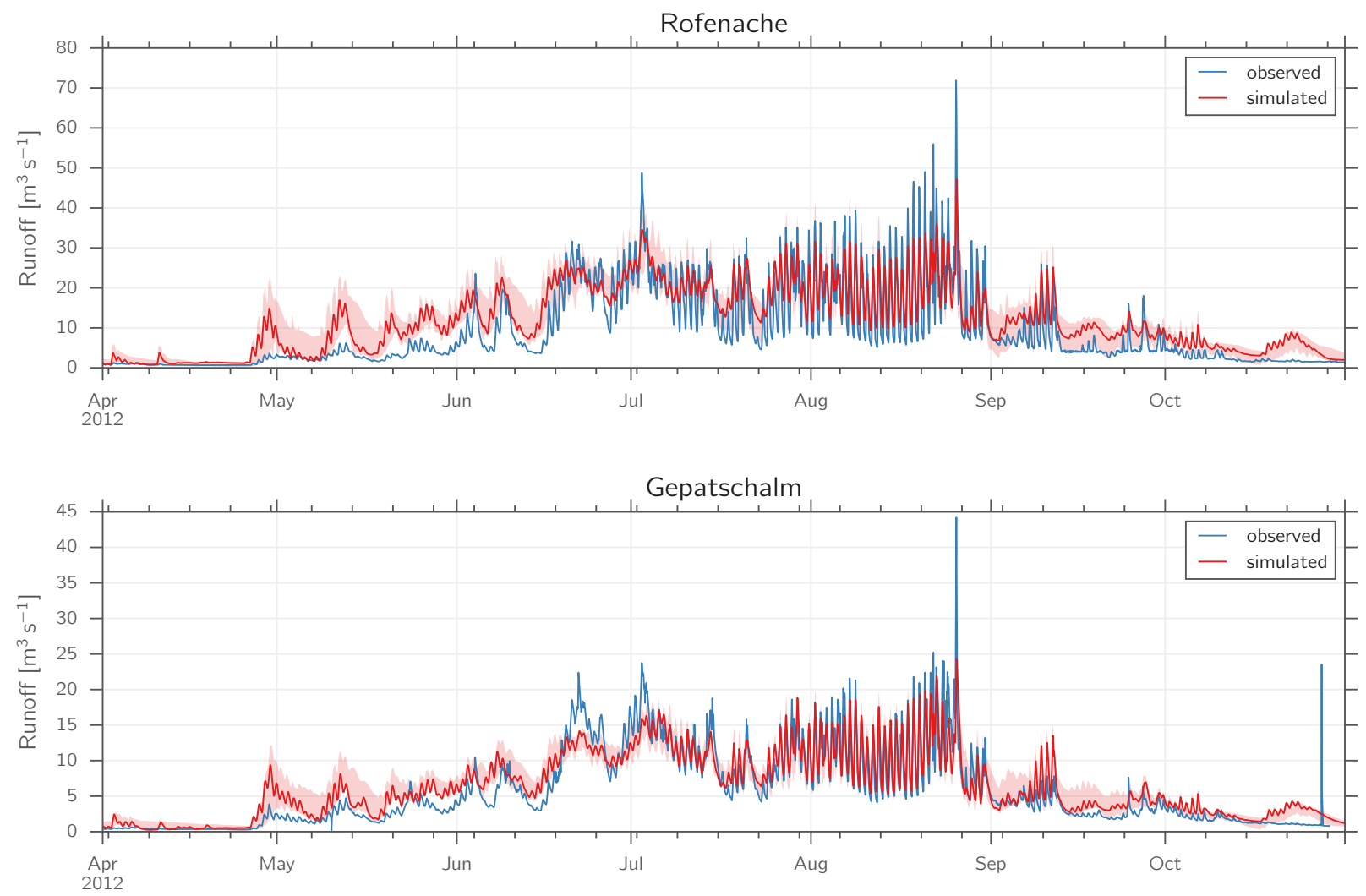

Figure S16: Observed (blue) and simulated (red) runoff for the Rofenache (top) and Gepatschalm (bottom) catchments in the year 2012. The red lines correspond to the runoff resulting from the best-performing parameter set in the calibration period, whereas the shaded areas represent the range of the 50 best-performing parameter sets. 